Check for updates

Cite this: RSC Adv., 2019, 9, 31466

Received 5th September 2019

Accepted 24th September 2019

DOI: 10.1039/c9ra07136a

rsc.li/rsc-advances

\section{Development of an intramolecular charge transfer- type colorimetric and fluorescence sensor for water by fusion with a juloidine structure and complexation with boron trifluoride $\uparrow$}

\begin{abstract}
Keiichi Imato, (D) Toshiaki Enoki and Yousuke Ooyama (DD *
An optical sensor with the ability to detect and determine water over a wide concentration range is highly desirable in the laboratory and industry. Here the sensitivity and spectral responses of an intramolecular charge transfer-type colorimetric and fluorescence sensor with $\beta$-carboline structure are tuned and improved significantly over various water contents in the organic solvent by fusion with an electrondonating juloidine structure and complexation with boron trifluoride $\left(\mathrm{BF}_{3}\right)$. The sensors, $\mathrm{ET}-1$ and $\mathrm{ET}-1-$ $\mathrm{BF}_{3}$, developed in this study can respond differently depending on water content. ET-1-BF 3 releases $\mathrm{BF}_{3}$ to generate ET-1 by addition of a trace amount of water, and ET-1 forms hydrogen bonds with one water molecule in low water contents and a hydrogen-bonded proton transfer complex with several water molecules in high water contents, accompanying gradual color and fluorescence changes. This work shows a promising approach to the sensitive detection and precise determination of water over the whole concentration range using a simple and practical method with optical sensors.
\end{abstract}

\section{Introduction}

The detection and determination of water are of great importance in industrial applications, including food inspection, biomedical and environmental monitoring, and manufacturing of pharmaceutical, electronic, and petroleum products. ${ }^{1}$ In synthetic chemistry, the presence of water in organic solvents causes serious problems, such as generation of by-products, quenching of reactions, lowering of the product yields, and furthermore, catastrophic dangers of fire and explosion. Particularly, in a large-scale industrial process, careful attention is paid to this impurity to avoid worst-case scenarios. Therefore, various analytical approaches and techniques have been developed to detect and determine water content in organic solvents. The standard Karl Fischer titration is the most popular method and allows for quantitative measurements of water over a wide range of the concentrations (0.001-100\% water) with high sensitivity and wide applicability for a large variety of samples; ${ }^{2,3}$ however, it has several limitations, e.g., instability, time-consuming procedure, and use of toxic chemical reagents and costly specialized instrumentation. Therefore, in recent years, the method using optical water sensors has attracted much attention because of its considerable advantages of

Department of Applied Chemistry, Graduate School of Engineering, Hiroshima University, 1-4-1 Kagamiyama, Higashi-Hiroshima 739-8527, Japan. E-mail: yooyama@hiroshima-u.ac.jp

$\dagger$ Electronic supplementary information (ESI) available. See DOI: 10.1039/c9ra07136a simple operation, low-cost fabrication, fast response, high sensitivity, non-destructive nature, and remote and in situ monitoring even by the naked eye. ${ }^{4}$ Although most research studies on the optical sensors have been focused on the detection and determination of a trace amount of water, ${ }^{5-28}$ sensors that can work over a wide range of water concentrations (similar to the range the Karl Fischer method can cover) are also required.

In the optical sensor method, water content can be determined by measurement and ratiometric analysis of the optical properties of small-quantity sensor molecules doped in sample solutions, i.e., wavelength, intensity, lifetime, and quantum yield of photoabsorption and photoluminescence. Therefore, the optical properties should be sensitive to water molecules and variable depending on the water content. Several strategies have been demonstrated to meet the requirement, such as intramolecular charge transfer (ICT) ${ }^{5-9}$ excited state intramolecular proton transfer (ESIPT), ${ }^{9-11}$ photo-induced electron transfer (PET), ${ }^{\mathbf{1 2}-18}$ aggregation-induced emission (AIE), ${ }^{\mathbf{7} 29,30}$ decoloration of hydrogen-bonding photochromic dyes, ${ }^{31}$ and other water-triggered mechanisms. ${ }^{19-28}$ Generally, in each system, there is a specific range of water concentration available for detection; AIE is observed in high water concentrations, ${ }^{7,29,30}$ whereas other systems exhibit optical changes in a relatively low concentration range..$^{5-28}$ In this context, a reasonable approach to incorporating two mechanisms into one sensor molecule has been developed to detect and determine water in organic solvent sensitively in a wide concentration range, including the 
combinations of ICT or PET and AIE, ${ }^{32-39}$ two water-induced reactions, ${ }^{40}$ and two ICT-related mechanisms, ${ }^{\mathbf{4 1 , 4 2}}$ with rare exceptions based on one mechanism. ${ }^{23,43-49}$ However, the pioneering systems still have several problems to be solved, such as the appearance of non-response ranges to variations in water content and the indiscernible small changes in the photoabsorption and fluorescence spectra as well as by the naked eye.

Herein, we report the tuning of sensitivity of optical sensors to water molecules and improvement in the spectral variations over a wide range of water content in an organic solvent. We focused on the $\beta$-carboline-based water sensor, $\mathbf{9 - M P},{ }^{\mathbf{5 0}}$ with a small electron donor-acceptor (D-A) structure and its complex with boron trifluoride $\left(\mathrm{BF}_{3}\right), \mathbf{9}-\mathbf{M P}-\mathbf{B F}_{3}{ }^{\mathbf{4 2}}$ as shown in Fig. 1, because they exhibit a unique multi-step response to increasing water content in organic solvent, i.e., release of $\mathrm{BF}_{3}$ (only in 9MP-BF $\mathbf{B}_{3}$ ), hydrogen bonding with one water molecule, and formation of hydrogen-bonded proton transfer complex (PTC $)^{50-58}$ with several water molecules, accompanying gradual spectral changes in photoabsorption and fluorescence based on the D-A structure and ICT. However, these systems also lack the capability to detect and determine water in moderate concentrations (ca. 10-40 wt\%) and show the indiscernible optical changes particularly in photoabsorption spectra also in the other ranges. ${ }^{42,50}$ Since the unique response is owing to the moderate basicity of the pyridinic nitrogen atom in the $\beta$-carboline skeleton, in this study, we modulated the basicity and enhanced the D-A and ICT characteristics by fusion of the $\beta$ carboline skeleton with a strong electron donor, juloidine, ${ }^{59}$ developing new water sensors, ET-1 and ET-1-BF $\mathbf{F}_{3}$. Their watersensing ability and sensing mechanisms were investigated in acetonitrile with various water contents, and the strategy for tuning of the sensitivity to water and improvement in spectral response over a wide range of water content were demonstrated.

\section{Experimental}

\section{General methods}

Melting points were measured using a Yanaco micro melting point apparatus MP model. IR spectra were recorded on a Shimadzu IRAffinity-1 spectrometer using the ATR method. Highresolution mass spectral data were acquired using a Thermo Fisher Scientific LTQ Orbitrap XL. ${ }^{1} \mathrm{H}$ NMR, ${ }^{13} \mathrm{C}$ NMR, and ${ }^{11} \mathrm{~B}$ NMR spectra were recorded using Varian-400 (400 $\mathrm{MHz})$ and Varian-500 (500 MHz) FT NMR spectrometers. Photoabsorption spectra were recorded using a Shimadzu UV-3150 spectrophotometer and fluorescence spectra were recorded using a HITACHI f-4500 fluorescence spectrometer. The determination of water in acetonitrile solution was done with MKC-610 and MKA610 Karl Fischer moisture titrators (Kyoto Electronics

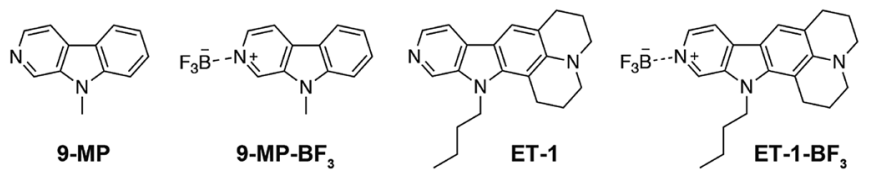

Fig. 1 Chemical structures of 9-MP, 9-MP-BF,$E T-1$, and $\mathrm{ET}-1-\mathrm{BF}_{3}$. manufacturing Co., Ltd.) based on Karl Fischer coulometric titration (relative standard deviation is below $0.3 \%$ in a measurement of methanol containing $1 \mathrm{mg}$ water) for below $1.0 \mathrm{wt} \%$ and volumetric titration for above $1.0 \mathrm{wt} \%$, respectively.

Synthesis of 13-butyl-2,3,5,6,7,13-hexahydro- $1 \mathrm{H}$-pyrido[3,2,1ij] pyrido $\left[4^{\prime}, 3^{\prime}: 4,5\right]$ pyrrolo[2,3-f]quinoline-boron trifluoride complex (ET-1-BF 3 ).

To a solution of ET-1 (ref. 59) (0.03 g, $0.09 \mathrm{mmol}$ ) in $6 \mathrm{~mL}^{\text {of }} \mathrm{Et}_{2} \mathrm{O}$ was added dropwise $47 \% \mathrm{BF}_{3}-\mathrm{OEt}_{2}(0.09 \mathrm{mmol})$ diluted with ether ( $2 \mathrm{~mL}$ ) for $30 \mathrm{~min}$, and then, the solution was stirred for $4 \mathrm{~h}$ at room temperature. The resulting precipitate was filtered and was washed by $\mathrm{Et}_{2} \mathrm{O}$ to give ET-1-BF 3 (0.03 g, 43\% yield) as a yellow solid; mp: $157-158{ }^{\circ} \mathrm{C}$; IR (ATR): $\tilde{\nu}=1611,1437$, $1030 \mathrm{~cm}^{-1} ;{ }^{1} \mathrm{H}$ NMR (400 MHz, $\left.\mathrm{CD}_{3} \mathrm{CN}\right): \delta=0.98(\mathrm{t}, J=7.4 \mathrm{~Hz}$, $3 \mathrm{H}), 1.38-1.42(\mathrm{~m}, 2 \mathrm{H}), 1.72-1.82(\mathrm{~m}, 2 \mathrm{H}), 2.00-2.04(\mathrm{~m}, 4 \mathrm{H}$, overlapping peak of residual proton in $\left.\mathrm{CD}_{3} \mathrm{CN}\right), 2.88(\mathrm{t}, \mathrm{J}=$ $6.2 \mathrm{~Hz}, 2 \mathrm{H}), 3.20(\mathrm{t}, J=6.4 \mathrm{~Hz}, 2 \mathrm{H}), 3.31-3.38(\mathrm{~m}, 4 \mathrm{H}), 4.48(\mathrm{t}, J=$ $7.8 \mathrm{~Hz}), 7.66$ (s, 1H), 7.95 (d, $J=6.2 \mathrm{~Hz}, 1 \mathrm{H}), 8.08$ (d, $J=6.2 \mathrm{~Hz}$, $1 \mathrm{H}), 8.51(\mathrm{~s}, 1 \mathrm{H}) \mathrm{ppm}$ (one aliphatic proton signal was not observed owing to overlapping resonances); ${ }^{13} \mathrm{C} \mathrm{NMR}(125 \mathrm{MHz}$, $\left.\mathrm{CD}_{3} \mathrm{CN}\right): \delta=13.96,20.57,21.68,22.22,23.99,46.85,50.36$, $51.77,102.23,110.82,113.29,121.40,121.41,121.83,129.62$, 135.69, 137.28, 145.37, $148.99 \mathrm{ppm} ;{ }^{11} \mathrm{~B}$ MNR $(160 \mathrm{MHz}$, $\left.\mathrm{CD}_{3} \mathrm{CN}\right): \delta=-1.13 \mathrm{ppm}$; HRMS (ESI): $m / z(\%):\left[\mathrm{M}+\mathrm{H}^{+}\right]$calcd for $\mathrm{C}_{22} \mathrm{H}_{25} \mathrm{~N}_{3}, 320.21212$, found 320.21240.

\section{Results and discussion}

The juloidine-conjugated $\beta$-carboline complexed with $\mathrm{BF}_{3}$, ET-1$\mathbf{B F}_{3}$, was effectively prepared by treating the corresponding $\beta$ carboline derivative, ET-1, with $\mathrm{BF}_{3}-\mathrm{OEt}_{2}$ and characterized by ${ }^{1} \mathrm{H}$ NMR, ${ }^{13} \mathrm{C}$ NMR, ${ }^{11} \mathrm{~B}$ NMR, and FT-IR measurements and high-resolution mass analysis.

The photoabsorption and fluorescence spectra of ET-1 and ET-1-BF 3 in acetonitrile are shown in Fig. 2. The photoabsorption maxima $\left(\lambda_{\max }^{\text {abs }}\right)$ of ET-1 and ET-1-BF $\mathbf{B}_{3}$ were observed at 365 and $436 \mathrm{~nm}$, respectively, which originate from the ICT

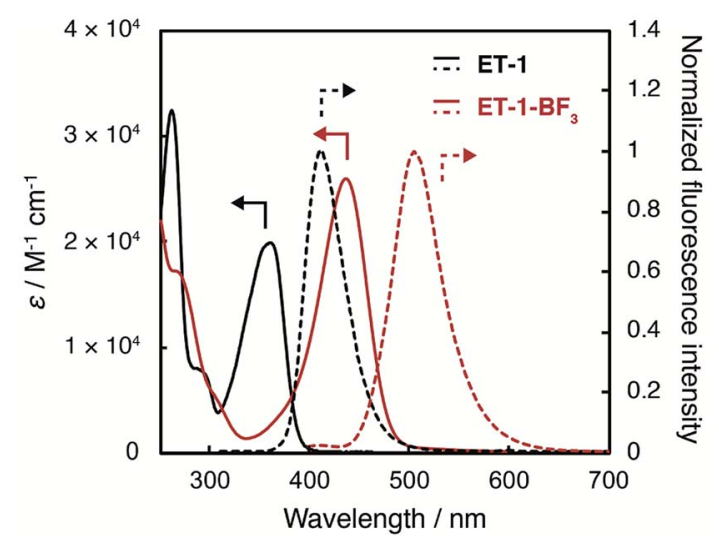

Fig. 2 Photoabsorption and fluorescence spectra of ET-1 and ET-1$\mathrm{BF}_{3}$ in acetonitrile ( $\lambda^{\mathrm{ex}}=310$ and $382 \mathrm{~nm}$ for $\mathrm{ET}-1$ and $\mathrm{ET}-1-\mathrm{BF}_{3}$, respectively). 
excitation from the electron-donating julolidine moiety to the electron-withdrawing pyridine moiety in ET-1 or to its complex with $\mathrm{BF}_{3}$ in $\mathbf{E T - 1}-\mathbf{B F}_{3}$. Because the strong electron-withdrawing ability of the pyridine complex with $\mathrm{BF}_{3}$ enhances the ICT characteristic, the photoabsorption maximum of ET-1-BF $\mathbf{3}$ was observed at longer wavelength region by $71 \mathrm{~nm}$ than that of ET1. Additionally, the molar excitation coefficient value $(\varepsilon)$ of ET-1$\left.\begin{array}{lll}\mathbf{B F}_{3} & \left(25900 \mathbf{M}^{-1}\right. & \mathrm{cm}^{-1}\end{array}\right)$ was higher than that of ET-1 (19 $900 \mathrm{M}^{-1} \mathrm{~cm}^{-1}$ ). Similarly, the corresponding fluorescence bands of ET-1 and ET-1-BF 3 appeared at 411 and $507 \mathrm{~nm}$ $\left(\lambda_{\max }^{\mathrm{fl}}\right)$, respectively, and the fluorescence quantum yields $\left(\Phi_{\mathrm{f}}\right)$ were 0.38 (ET-1) and $0.65\left(\mathbf{E T - 1}-\mathbf{B F}_{3}\right)$. These results indicate that the complexation of ET-1 with $\mathrm{BF}_{3}$ caused not only the bathochromic shifts of the photoabsorption and fluorescence bands but also the increases in $\varepsilon$ and $\Phi_{\mathrm{f}}$ values. Furthermore,

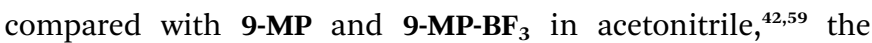
fusion with juloidine could improve their photophysical properties $\left(\lambda_{\max }^{\mathrm{abs}}=358\right.$ and $388 \mathrm{~nm}, \varepsilon=5800$ and $3300 \mathrm{M}^{-1} \mathrm{~cm}^{-1}$, $\lambda_{\max }^{\mathrm{fl}}=368$ and $458 \mathrm{~nm}$, and $\Phi_{\mathrm{f}}=0.04$ and 0.52 for 9-MP and 9$\mathbf{M P}-\mathbf{B F}_{3}$, respectively).

In order to investigate the ability of ET-1 and ET-1-BF $\mathbf{F}_{3}$ as optical sensors for water in organic solvent, the photoabsorption and fluorescence measurements were performed in acetonitrile with various water contents (Fig. 3 and 4). In the case of ET-1, the photoabsorption band at around $360 \mathrm{~nm}$ slightly increased in intensity and bathochromically shifted with increase in water content up to $11 \mathrm{wt} \%$, and two isosbestic points were observed at 298 and $354 \mathrm{~nm}$ (Fig. 3b). These small spectral changes can be ascribed to the formation of the hydrogen-bonded complex (ET-1- $\left.\mathbf{H}_{2} \mathbf{O}\right)$ between the pyridinic nitrogen atom and one water molecule. ${ }^{42,50-58}$ Above $11 \mathrm{wt} \%$, the photoabsorption band decreased in intensity and red-shifted distinctly, while a new photoabsorption band appeared simultaneously at around $430 \mathrm{~nm}$ (Fig. 3c). The new band is assignable to the ICT band of the hydrogen-bonded PTC (ET-1-H $\left.{ }^{+}\right)$ formed by the proton transfer from water molecule to the pyridinic nitrogen atom. Since the photoabsorption spectra of 9MP changed negligibly over the whole range of water content, ${ }^{42,50}$ these results indicate that the fusion of juloidine and the enhanced ICT characteristic improved its spectral responses to water. Similar behavior was also observed in the fluorescence spectra of ET-1. The solution showed a small redshift and increase in intensity of the fluorescence band at around $420 \mathrm{~nm}$ by addition of water up to $11 \mathrm{wt} \%$ (Fig. 3e), indicating the formation of the hydrogen-bonded complex (ET$\left.\mathbf{1}-\mathbf{H}_{2} \mathrm{O}\right)$. From $11 \mathrm{wt} \%$, the intensity of the fluorescence band started decreasing significantly, while a new band originating from the hydrogen-bonded PTC (ET-1-H $\left.{ }^{+}\right)$simultaneously appeared at around $510 \mathrm{~nm}$ and increased in intensity with an isoemissive point at $475 \mathrm{~nm}$ (Fig. $3 \mathrm{f}$ ). In the previous study, ${ }^{59}$ these spectral changes were observed by not increasing the static dielectric constant of solvent but changing the solvent to hydrogen-bonding protic one. From these results, we concluded that the hydrogen-bonded complex $\left(\mathbf{E T}-\mathbf{1}-\mathbf{H}_{2} \mathbf{O}\right)$ started forming
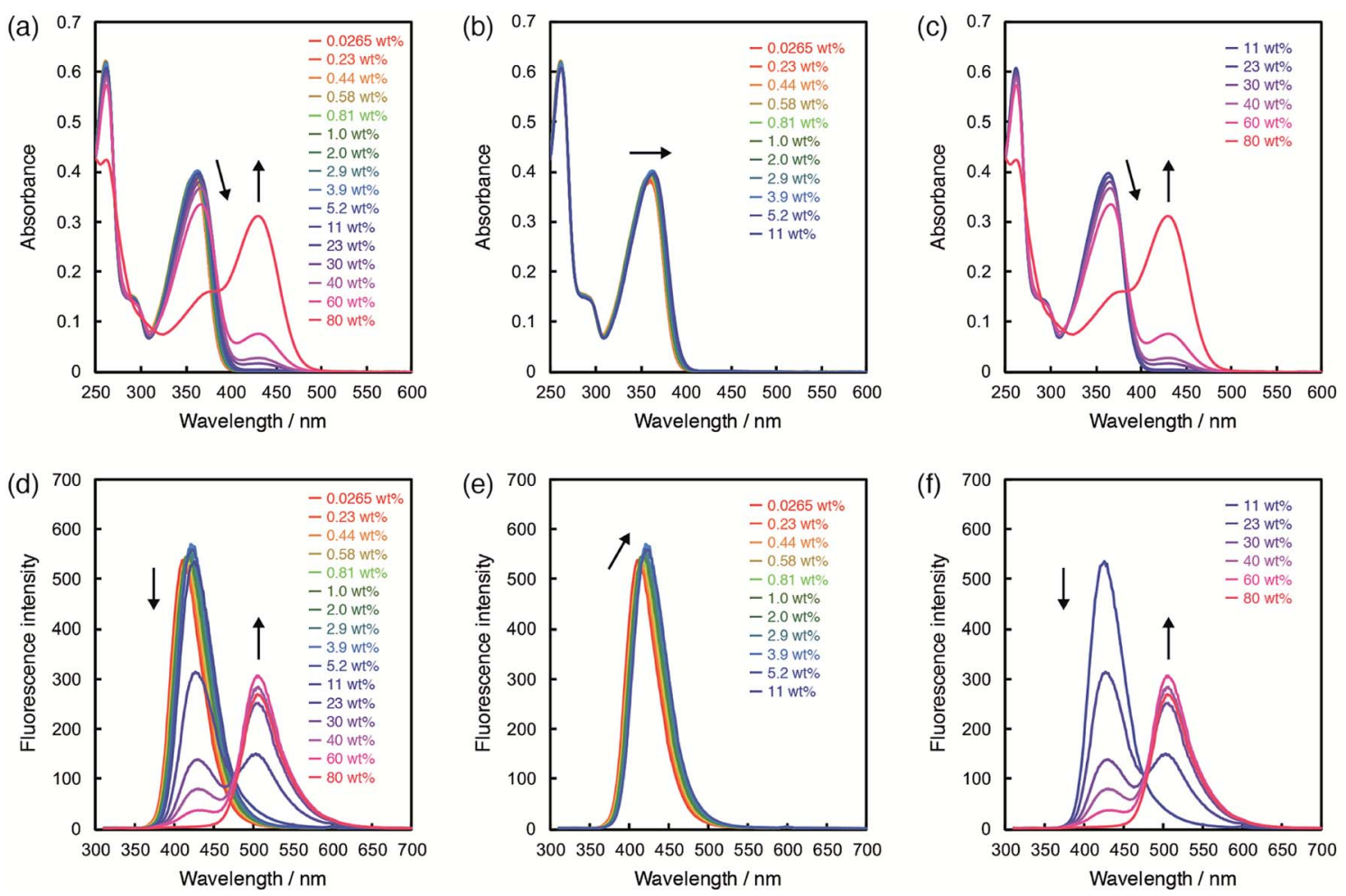

Fig. 3 Photoabsorption spectra of ET-1 ( $c=2.0 \times 10^{-5} \mathrm{M}$ ) in acetonitrile containing (a) $0.0265-80 \mathrm{wt} \%$, (b) $0.0265-11 \mathrm{wt} \%$, and (c) $11-80 \mathrm{wt} \%$ of water. Fluorescence spectra of ET-1 ( $c=2.0 \times 10^{-5} \mathrm{M}, \lambda^{\mathrm{ex}}=302 \mathrm{~nm}$ ) in acetonitrile containing (d) $0.0265-80 \mathrm{wt} \%$, (e) $0.0265-11 \mathrm{wt} \%$, and (f) $11-80 \mathrm{wt} \%$ of water. 

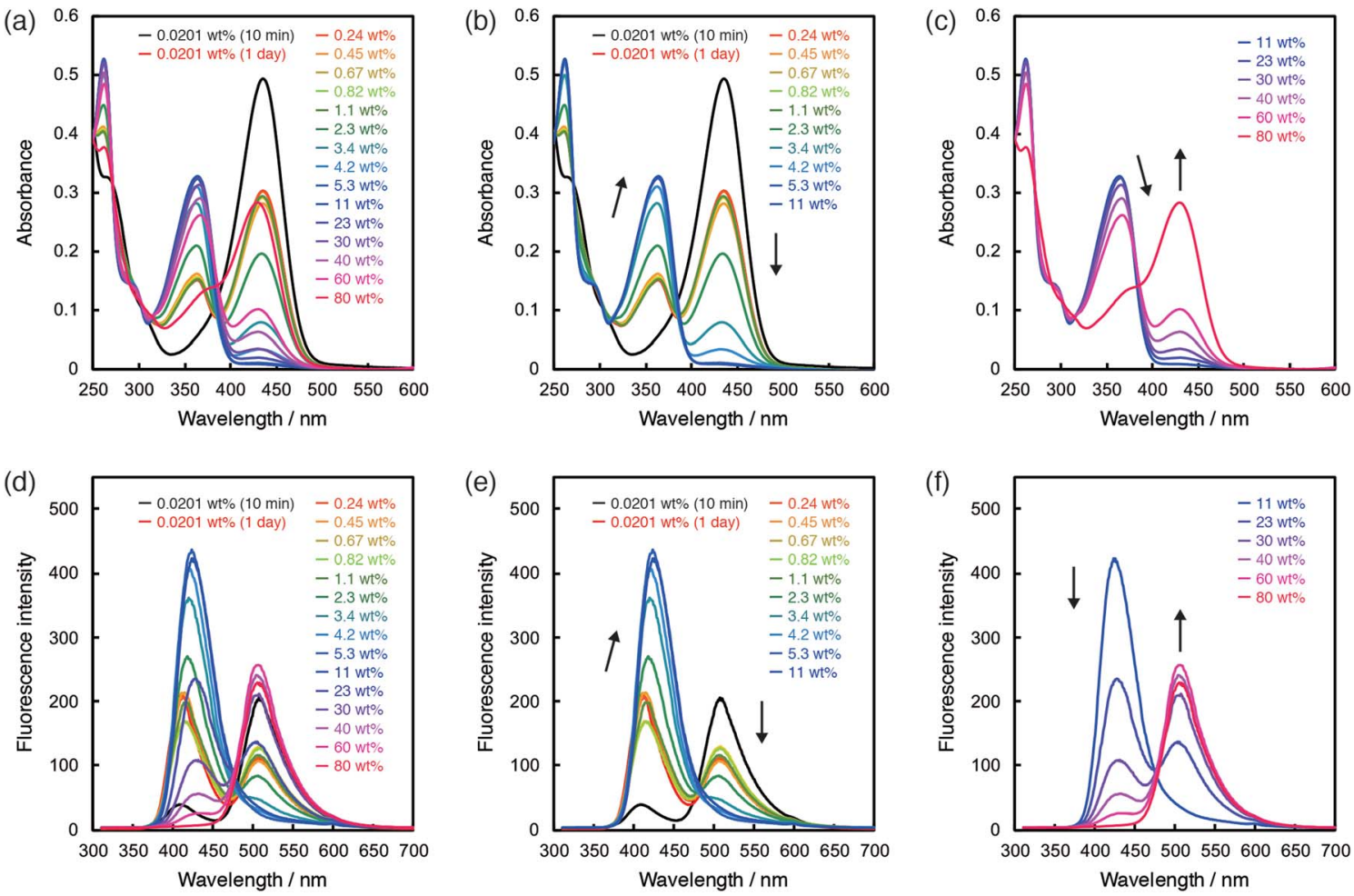

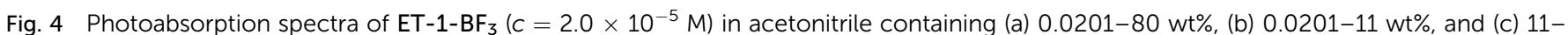

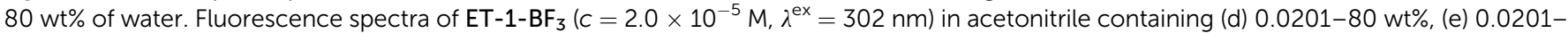
$11 \mathrm{wt} \%$, and (f) $11-80 \mathrm{wt} \%$ of water.

from a trace content of water, followed by the simultaneous generation of the hydrogen-bonded PTC (ET-1-H ${ }^{+}$) above $11 \mathrm{wt} \%$. Additionally, it is noteworthy that ET-1 started forming the hydrogen-bonded PTC from the lower water content (11 wt\%) compared to 9-MP (from $40 \mathrm{wt} \%)^{42,50}$ due to the enhanced basicity of the pyridinic nitrogen atom in ET-1 and resulting promotion of the PTC formation, indicating a successful tuning of the sensitivity over a wide range of water content.

In the case of $\mathbf{E T}-\mathbf{1}-\mathbf{B F}_{3}$, the photoabsorption and fluorescence spectral responses to water were complicated. First, we examined the time dependence of the spectra after addition of a tiny amount of water. In the photoabsorption and fluorescence spectra, large differences were observed between the ET$\mathbf{1}-\mathbf{B F}_{\mathbf{3}}$ acetonitrile solutions that were stored in the dark for $10 \mathrm{~min}$ or 1 day after addition of $0.0201 \mathrm{wt} \%$ of water (Fig. $4 \mathrm{a}$ and d). The longer storage time caused significant decreases in intensity of the photoabsorption band at around $430 \mathrm{~nm}$ and fluorescence band at around $510 \mathrm{~nm}$ and also increases in intensity of the photoabsorption band at around $360 \mathrm{~nm}$ and fluorescence band at around $420 \mathrm{~nm}$. Because the timedependent spectral changes are attributed to the waterinduced release of $\mathrm{BF}_{3}$ and generation of ET-1, ${ }^{\mathbf{4 1 , 4 2}}$ the results indicate that the reaction occurs with a trace amount of water but takes a relatively long time. Therefore, we employed the solutions stored in the dark for 1 day after adding various amounts of water for the following photoabsorption and fluorescence measurements. By the addition of water up to $11 \mathrm{wt} \%$, the photoabsorption band at around $430 \mathrm{~nm}$ drastically decreased in intensity and almost disappeared with simultaneous increase of that at around $360 \mathrm{~nm}$, which originates from ET-1 generated as a result of the $\mathrm{BF}_{3}$ release (Fig. 4b). From $11 \mathrm{wt} \%$, the photoabsorption band at around $360 \mathrm{~nm}$ decreased in intensity, while that at around $430 \mathrm{~nm}$ reappeared and increased, indicating the formation of the hydrogen-bonded PTC (ET-1-H ${ }^{+}$) (Fig. 4c). The formation of the hydrogenbonded complex (ET-1- $\mathbf{H}_{2} \mathbf{O}$ ) is seen from the bathochromic shift of the photoabsorption band at around $360 \mathrm{~nm}$ in a wide range above $2.3 \mathrm{wt} \%$ (below $40 \mathrm{wt} \%$ ) (Fig. $4 \mathrm{~b}$ and c). In the spectra, isosbestic points were observed at 272 and $293 \mathrm{~nm}$ below $2.3 \mathrm{wt} \%$ and 272,305 , and $386 \mathrm{~nm}$ above $40 \mathrm{wt} \%$ of water content. In the corresponding fluorescence spectra (Fig. 4d-f), the intensity of the band at around $510 \mathrm{~nm}$ originating from ET$\mathbf{1}-\mathbf{B F}_{3}$ decreased with increase of that at around $420 \mathrm{~nm}$ originating from ET-1 below 11 wt\% of water content (Fig. 4e). In the range, the band at around $420 \mathrm{~nm}$ red-shifted with increase in water content, indicating the simultaneous formation of ET-1$\mathbf{H}_{2} \mathbf{O} .^{42,50-58}$ Above $11 \mathrm{wt} \%$, the fluorescence band at around $420 \mathrm{~nm}$ decreased in intensity, while that at around $510 \mathrm{~nm}$ significantly increased with an isoemissive point at $475 \mathrm{~nm}$, due to the generation of ET-1-H ${ }^{+}$(Fig. 4f). From the comparison between Fig. 3 and 4, it can be concluded that the sensitivity and spectral response to water could be further improved in the low water contents by the complexation of the juloidine-conjugated $\beta$-carboline sensor (ET-1) with $\mathrm{BF}_{3}$. 
To evaluate the optical sensing ability in detail, the peak intensities of photoabsorption and fluorescence bands were plotted against the water content in acetonitrile solutions of ET$\mathbf{1}$ (Fig. 5) and ET-1-BF 3 (Fig. 6). In the case of ET-1, although the maximum intensities of the photoabsorption bands at around $360\left(A_{360}\right)$ and $430\left(A_{430}\right) \mathrm{nm}$ were almost unchanged upon increase in water content below $11 \mathrm{wt} \%$ (Fig. 5b), $A_{360}$ decreased and $A_{430}$ increased linearly as a function of water content in the range of $11-60 \mathrm{wt} \%$ (Fig. $5 \mathrm{c}$ ). The slopes $\left(m_{\mathrm{s}}\right)$ in the plots and the correlation coefficient values $\left(R^{2}\right)$ for the calibration curves are -0.001 and 0.97 for $A_{360}$ and 0.002 and 0.91 for $A_{430}$, respectively. On the other hand, the maximum intensities of the fluorescence bands at around $420\left(\mathrm{FL}_{420}\right)$ and $510\left(\mathrm{FL}_{510}\right) \mathrm{nm}$ increased with increase in the water content even below $11 \mathrm{wt} \%$ due to the formation of ET-1- $\mathbf{H}_{2} \mathbf{O}$ (Fig. 5e). The $m_{\mathrm{s}}$ and $R^{2}$ values for $\mathrm{FL}_{510}$ are 2.3 and 0.99 , respectively, which show good response and linearity. Moreover, the plots of $\mathrm{FL}_{420}$ and $\mathrm{FL}_{510}$ show significant decrease and increase, respectively, with increasing water content above $11 \mathrm{wt} \%$ due to the generation of ET-1-H ${ }^{+}$(Fig. 5f). The linear relationships were also observed between the fluorescence intensities $\left(\mathrm{FL}_{420}\right.$ and $\left.\mathrm{FL}_{510}\right)$ and water content in the 11-40 wt\% range. The $m_{\mathrm{s}}$ and $R^{2}$ values are -16 and 0.95 for $\mathrm{FL}_{420}$ and 9.0 and 0.95 for $\mathrm{FL}_{510}$, respectively. These results, i.e., the linear relationships observed over the wide range of water content, suggest that the precise determination of water in organic solvent is possible over a wide range by using a small amount of ET-1 as an optical sensor.

ET-1-BF 3 showed distinctly different behavior from ET-1 below $11 \mathrm{wt} \%$ of water content (Fig. 6). The photoabsorption and fluorescence intensities drastically changed with increasing water content, although thresholds were observed at around $1 \mathrm{wt} \%$ (Fig. 6b and f). The slow release of $\mathrm{BF}_{3}$ and incomplete conversion within the reaction time ( 1 day) would cause the appearance of the thresholds. Indeed, the thresholds disappeared in the plots obtained using the solutions stored in the dark for 2 days (Fig. S1, $\mathrm{ESI} \dagger)$. In the water content range of 1.1-4.2 wt $\%, A_{360}$ increased but $A_{430}$ decreased in a linear fashion with increase of water content (Fig. 6b). The $m_{\mathrm{s}}$ and $R^{2}$ values are 0.05 and 0.99 for $A_{360}$ and -0.09 and 0.99 for $A_{430}$, respectively. Similar contrasting behavior were observed between the plots of $\mathrm{FL}_{420}$ and $\mathrm{FL}_{510}$ in the low content range with linear relationships (Fig. 6f). The large $m_{\mathrm{s}}$ values (68 for $\mathrm{FL}_{420}$ and -28 for $\mathrm{FL}_{510}$ ) and the $R^{2}$ values close to 1 ( 0.99 for $\mathrm{FL}_{420}$ and $\mathrm{FL}_{510}$ ) indicate a superior performance (sensitivity and accuracy) of $\mathbf{E T}-\mathbf{1}-\mathbf{B F}_{3}$ as a water sensor, although the presence of thresholds precludes estimation of the detection limits. In the 4.2$11 \mathrm{wt} \%$ range, only slight changes were observed in the photoabsorption and fluorescent intensities (Fig. $6 \mathrm{c}$ and g). However, in the higher water content range of $11-60 \mathrm{wt} \%, A_{360}$ and $A_{430}$ distinctly changed $\left(m_{\mathrm{s}}=-0.002\right.$ and 0.002 , respectively) with linear relationships $\left(R^{2}=0.96\right.$ and 0.98 , respectively) due to the formation of ET-1-H ${ }^{+}$(Fig. 6d), as is the case for ET-1 (Fig. 5c). Moreover, $\mathrm{FL}_{420}$ decreased and $\mathrm{FL}_{510}$ increased linearly as a function of the water content in the $11-40 \mathrm{wt} \%$ range $\left(m_{\mathrm{s}}=-0.002\right.$ and 0.002 and $R^{2}=0.95$ and 0.96 , respectively) (Fig. $6 \mathrm{~h}$ ). These values show good agreement with those observed in the ET-1 solutions (Fig. 5f). Therefore, the complexation of ET-1 with $\mathrm{BF}_{3}$ could significantly tune and improve the sensitivity and response, particularly in the low water content range.
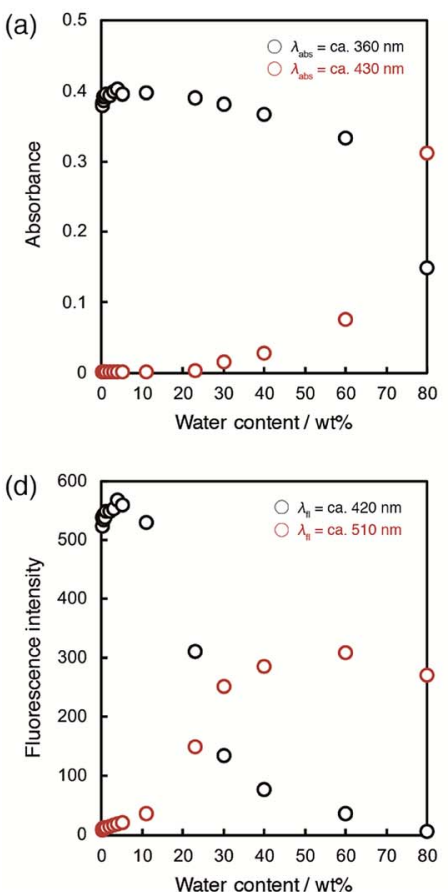
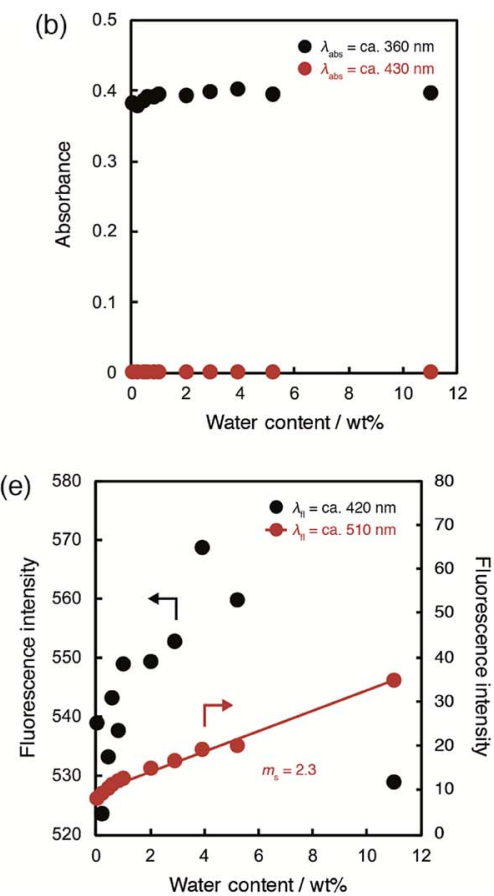
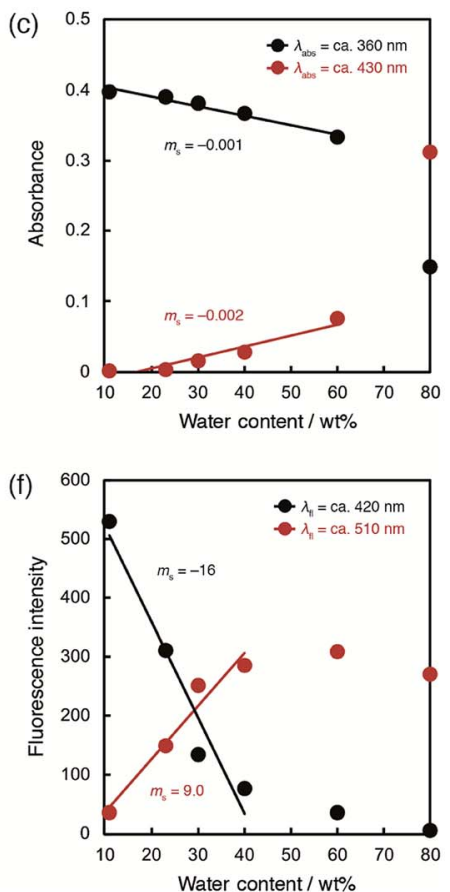

Fig. 5 Peak intensities of photoabsorption bands at around 360 and $430 \mathrm{~nm}$ in acetonitrile solutions of ET-1 with (a) $0.0265-80$ wt\%, (b) $0.0265-11 \mathrm{wt} \%$, and (c) $11-80 \mathrm{wt} \%$ of water. Peak intensities of fluorescence bands at around 420 and $510 \mathrm{~nm}\left(\lambda^{\mathrm{ex}}=302 \mathrm{~nm}\right)$ in acetonitrile solutions of ET-1 with (d) $0.0265-80$ wt\%, (e) $0.0265-11$ wt\%, and (f) $11-80$ wt\% of water. 

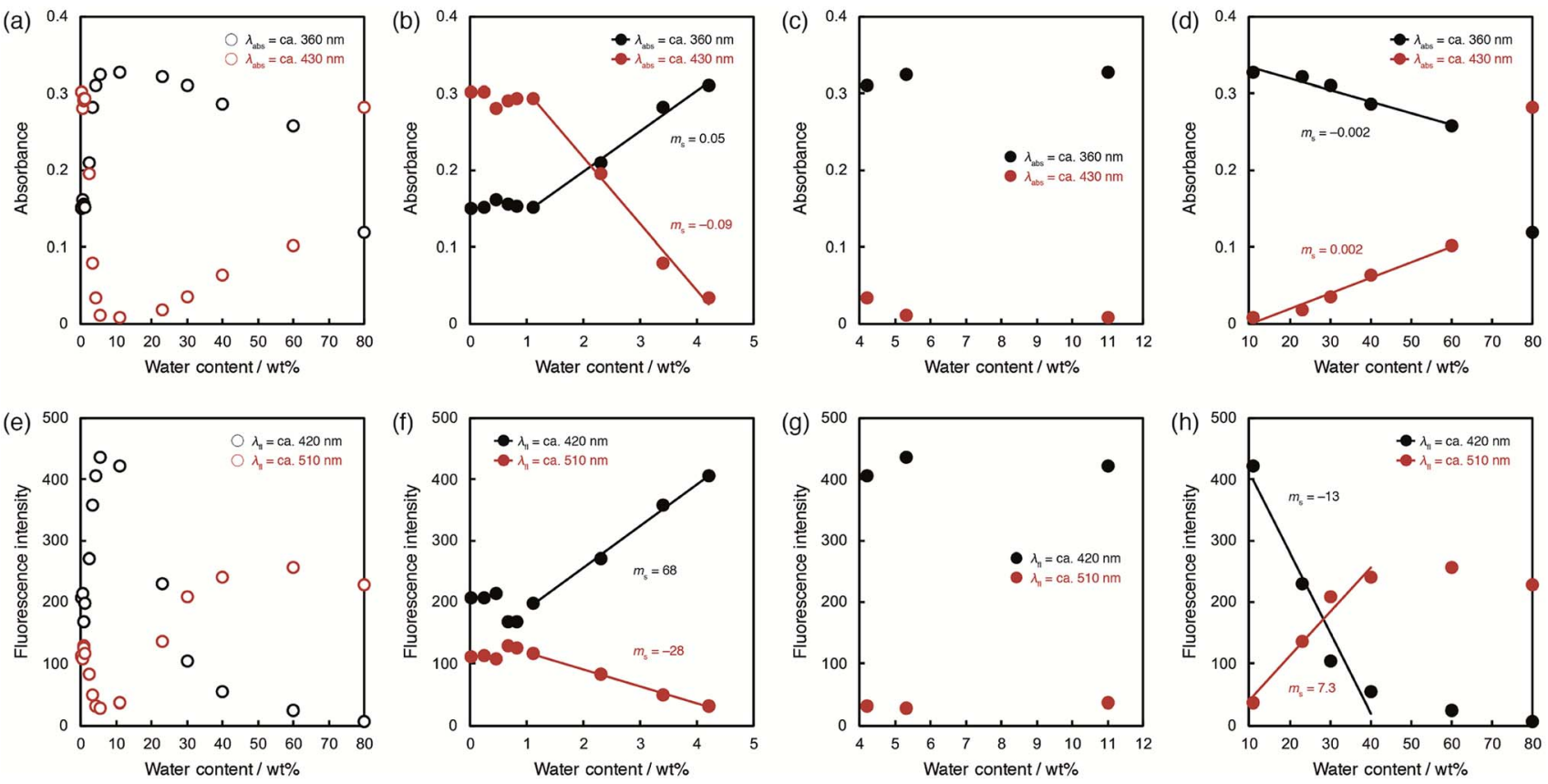

Fig. 6 Peak intensities of photoabsorption bands at around 360 and $430 \mathrm{~nm}$ in acetonitrile solutions of ET-1-BF 3 with (a) $0.0201-80$ wt\%, (b) $0.0201-4.2 \mathrm{wt} \%$, (c) $4.2-11 \mathrm{wt} \%$, and (d) $11-80 \mathrm{wt} \%$ of water. Peak intensities of fluorescence bands at around 420 and $510 \mathrm{~nm}\left(\lambda^{\mathrm{ex}}=302 \mathrm{~nm}\right)$ in

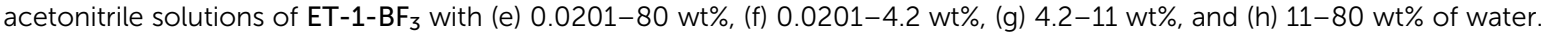

To elucidate the mechanisms for the detection of water, ${ }^{1} \mathrm{H}$ NMR spectra of ET-1 and ET-1-BF 3 in $\mathrm{CD}_{3} \mathrm{CN}$ with and without $10 \mathrm{wt} \%$ of deuterated water were obtained (Fig. 7). The complexation with $\mathrm{BF}_{3}$ significantly shifted the peaks of the aromatic protons, $\mathrm{H}_{\mathrm{a}}$ and $\mathrm{H}_{\mathrm{b}}$, in ET-1 to the higher magnetic field and those of the aromatic $\mathrm{H}_{\mathrm{c}}$ and $\mathrm{H}_{\mathrm{d}}$ to the lower field, while the aliphatic protons were affected little (Fig. 7a and b). ${ }^{59}$ The addition of $10 \mathrm{wt} \%$ of $\mathrm{D}_{2} \mathrm{O}$ to the ET-1 solution, which generates ET-1- $\mathbf{D}_{\mathbf{2}} \mathrm{O}$ as discussed above, caused large upfield peak shifts of $\mathrm{H}_{\mathrm{a}}$ and $\mathrm{H}_{\mathrm{b}}$ close to the pyridinic nitrogen atom, a slight downfield shift of $\mathrm{H}_{c}$, and no shift of $\mathrm{H}_{\mathrm{d}}$ distant from the nitrogen atom (Fig. 7c). These changes are similar but lesser extents to the $\mathrm{BF}_{3}$ complexation. In the ET-1-BF $\mathbf{3}$ solution with $10 \mathrm{wt} \%$ of $\mathrm{D}_{2} \mathrm{O}$, the $\mathrm{H}_{\mathrm{d}}$ peak shifted to the position close to those observed in the ET-1 solutions with and without $10 \mathrm{wt} \%$ of $\mathrm{D}_{2} \mathrm{O}$ (Fig. 7a and c), indicating the release of some $\mathrm{BF}_{3}$ (Fig. 7d). The appearance of the $\mathrm{H}_{\mathrm{a}}, \mathrm{H}_{\mathrm{b}}$, and $\mathrm{H}_{\mathrm{c}}$ peaks between those of the ET1 solution containing $10 \mathrm{wt} \%$ of $\mathrm{D}_{2} \mathrm{O}$ and the ET-1-BF $\mathbf{B F}_{3}$ solution without $\mathrm{D}_{2} \mathrm{O}$ also supports the partial release. Therefore, the ET1- $\mathrm{BF}_{3}$ solution containing $10 \mathrm{wt} \%$ of $\mathrm{D}_{2} \mathrm{O}$ can be considered to be a mixture of ET-1-BF 3 , ET-1, and ET-1-D $\mathbf{D}_{2} \mathbf{O}$. Based on the results obtained in the photoabsorption, fluorescence, and ${ }^{1} \mathrm{H}$
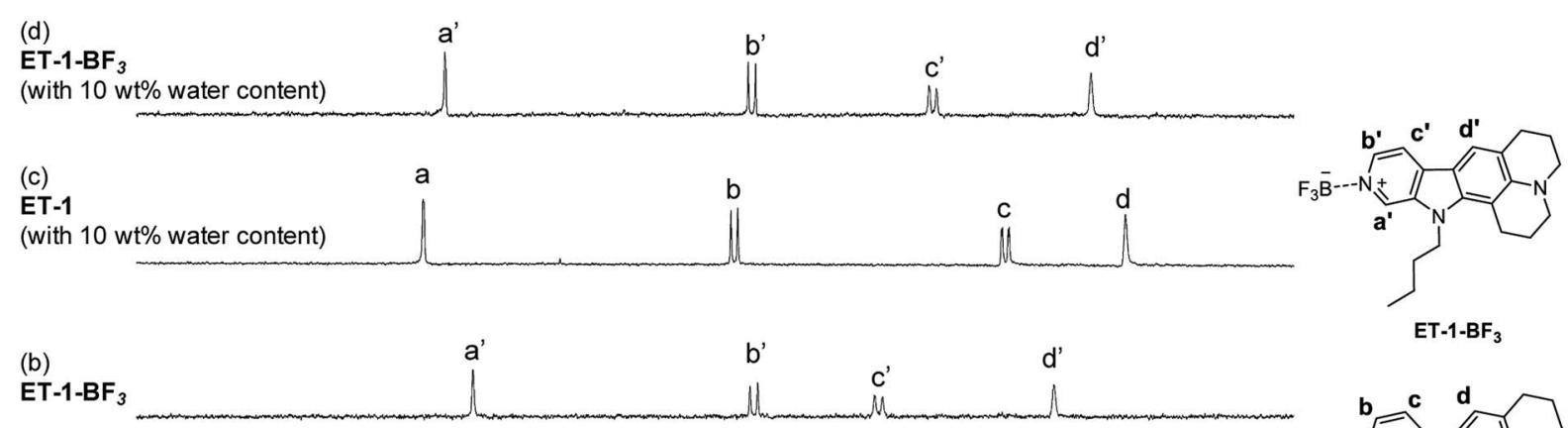

(a)

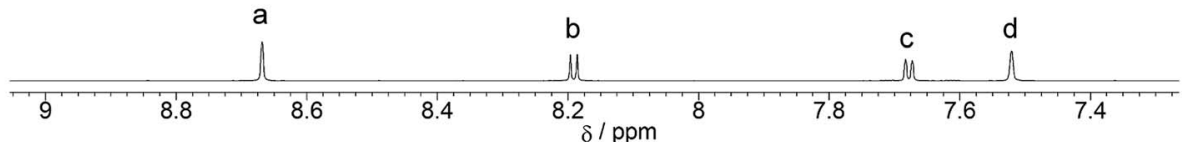

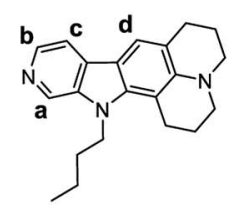

ET-1

Fig. $7{ }^{1} \mathrm{H}$ NMR spectra of (a) ET-1 and (b) ET-1-BF in $\mathrm{CD}_{3} \mathrm{CN}$ and (c) ET-1 and (d) ET-1-BF 3 in $C D_{3} C N$ containing 10 wt\% of $\mathrm{D}_{2} \mathrm{O}\left(\mathrm{c}=1.0 \times 10^{-4}\right.$ M). 


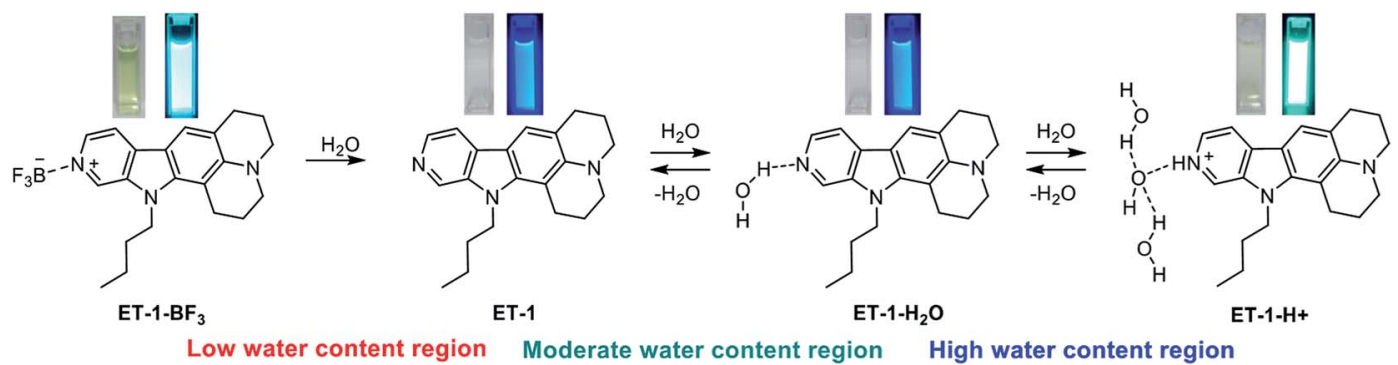

Fig. 8 Proposed mechanisms for the detection of water in organic solvent by the colorimetric and fluorescent sensor ET-1-BF 3 . Photographs are color (left) and fluorescence (right) images of the acetonitrile solutions with various amounts of water.

NMR measurements and previous studies, ${ }^{\mathbf{4 1 , 4 2 , 5 0 - 5 9}}$ we proposed plausible mechanisms for the detection of water in organic solvent using $\mathbf{E T - 1 - \mathbf { B F } _ { 3 }}$ in Fig. 8. In the region of low water content, a number of complex release $\mathrm{BF}_{3}$ below ca. $10 \mathrm{wt} \%,{ }^{41,42}$ and the resultant ET-1 starts forming the hydrogen-bonded

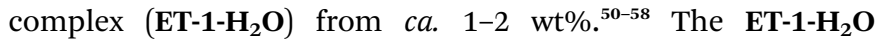
forms over a wide range of water content. In the region of high water content above $c a .10 \mathrm{wt} \%$, the hydrogen-bonded PTC (ET1-H ${ }^{+}$) gradually generates. ${ }^{50-58}$ Previously, a photochromic dye sensor with intramolecular hydrogen bonding that can detect hydrogen bonding characters of media has been developed. ${ }^{31}$ ET-1 detects water based on hydrogen bonding with water molecules similarly to the photochromic sensor. However, differently from the sensor, ET-1 stepwisely forms two complexes hydrogen-bonded with one water molecule or several water molecules, as the precursor 9-MP does. ${ }^{50-58}$ Indeed, the responses of ET-1-BF $\mathbf{B}_{\mathbf{3}}$ to water were demonstrated visually as shown in Fig. 8. The yellow color of the ET-1-BF $\mathbf{B}_{3}$ solution faded away with increasing water content due to the release of $\mathrm{BF}_{3}$ and subsequent formation of $\mathbf{E T}-\mathbf{- 1}-\mathbf{H}_{2} \mathbf{O}$, followed by the restoration

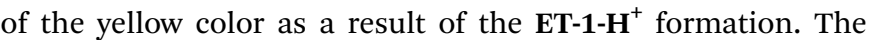
fluorescence color also changed in the order of light blue, blue, and green, together with the color changes.

\section{Conclusions}

We have developed ICT-type colorimetric and fluorescence sensors, ET-1 and ET-1-BF , $_{3}$, for detection and determination of water over a wide range of the concentration in organic solvent. The sensors can response to water differently depending on the content. In the range of low water content (below ca. $10 \mathrm{wt} \%$ ), ET-1-BF 3 releases BF $_{3}$ to generate ET-1, and ET-1 forms the hydrogen-bonded complex with one water molecule (ET-1-H $\left.\mathbf{H}_{2} \mathbf{O}\right)$. In higher water contents (above ca. $10 \mathrm{wt} \%$ ), the hydrogenbonded PTC (ET-1-H ${ }^{+}$) gradually generates. Compared with the previous ICT-type sensors with $\beta$-carboline structure (9-MP and $\mathbf{9}-\mathbf{M P}-\mathbf{B F}_{3}$ ), the sensitivity and spectral response to water are significantly improved over a wide concentration range by the fusion with the electron-donating juloidine and complexation with $\mathrm{BF}_{3}$. The juloidine conjugation enhances the basicity of the pyridinic nitrogen atom and the ICT characteristic. The $\mathrm{BF}_{3}$ complexation contributes to the improvements particularly in the low water contents. This work shows a useful approach to tuning and improvement of optical sensors for sensitive detection and precise determination of water over various concentrations.

\section{Conflicts of interest}

There are no conflicts to declare.

\section{Acknowledgements}

This work was supported by Grant-in-Aids for Scientific Research on Innovative Areas "Soft Crystals" (No. 2903) (JSPS KAKENHI Grant No. 18H04520) and for Scientific Research (B) (JSPS KAKENHI Grant No. 19H02754) and by Mukai Science and Technology Foundation.

\section{Notes and references}

1 C. Harris, Talanta, 1972, 19, 1523.

2 Y. Y. Liang, Anal. Chem., 1990, 62, 2504.

3 S. K. MacLeod, Anal. Chem., 1991, 63, 557A.

4 H. S. Jung, P. Verwilst, W. Y. Kim and J. S. Kim, Chem. Soc. Rev., 2016, 45, 1242.

5 D. Citterio, K. Minamihashi, Y. Kuniyoshi, H. Hisamoto, S.-I. Sasaki and K. Suzuki, Anal. Chem., 2001, 73, 5339.

6 L. Ding, Z. Zhang, X. Li and J. Su, Chem. Commun., 2013, 49, 7319.

7 Y. Zhang, D. Li, Y. Li and J. Yu, Chem. Sci., 2014, 5, 2710.

8 P. Kumar, R. Kaushik, A. Ghosh and D. A. Jose, Anal. Chem., 2016, 88, 11314.

9 H.-L. Qian, C. Dai, C.-X. Yang and X.-P. Yan, ACS Appl. Mater. Interfaces, 2017, 9, 24999.

10 B. Bhattacharya, A. Halder, L. Paul, S. Chakrabarti and D. Ghoshal, Chem.-Eur. J., 2016, 22, 14998.

11 L. Chen, J.-W. Ye, H.-P. Wang, S.-Y. Yin, Z.-W. Wei, L.-Y. Zhang, K. Wu, Y.-N. Fan, M. Pan and C.-Y. Su, Nat. Commun., 2017, 8, 15985.

12 Y. Ooyama, A. Matsugasako, K. Oka, T. Nagano, M. Sumomogi, K. Komaguchi, I. Imae and Y. Harima, Chem. Commun., 2011, 47, 4448.

13 Y. Ooyama, A. Matsugasako, Y. Hagiwara, J. Ohshita and Y. Harima, RSC Adv., 2012, 2, 7666.

14 Y. Ooyama, K. Uenaka, A. Matsugasako, Y. Harima and J. Ohshita, RSC Adv., 2013, 3, 23255. 
15 Y. Ooyama, K. Furue, K. Uenaka and J. Ohshita, RSC Adv., 2014, 4, 25330.

16 Y. Ooyama, S. Aoyama, K. Furue, K. Uenaka and J. Ohshita, Dyes Pigm., 2015, 123, 248.

17 Y. Ooyama, M. Hato, T. Enoki, S. Aoyama, K. Furue, N. Tsunoji and J. Ohshita, New J. Chem., 2016, 40, 7278.

18 S. Guo, Y. Ma, S. Liu, Q. Yu, A. Xu, J. Han, L. Wei, Q. Zhao and W. Huang, J. Mater. Chem. C, 2016, 4, 6110.

19 Q. Gao, Y. Xiu, G.-D. Li and J.-S. Chen, J. Mater. Chem., 2010, 20, 3307.

20 Q. Deng, Y. Li, J. Wu, Y. Liu, G. Fang, S. Wang and Y. Zhang, Chem. Commun., 2012, 48, 3009.

21 S. Ishihara, J. Labuta, T. Šikorský, J. V. Burda, N. Okamoto, H. Abe, K. Ariga and J. P. Hill, Chem. Commun., 2012, 48, 3933.

22 K. Zhao, T. Liu, G. Wang, X. Chang, D. Xue, K. D. Belfield and Y. Fang, J. Phys. Chem. B, 2013, 117, 5659.

23 G. Men, G. Zhang, C. Liang, H. Liu, B. Yang, Y. Pan, Z. Wang and S. Jiang, Analyst, 2013, 138, 2847.

24 A. Douvali, A. C. Tsipis, S. V. Eliseeva, S. Petoud, G. S. Papaefstathiou, C. D. Malliakas, I. Papadas, G. S. Armatas, I. Margiolaki, M. G. Kanatzidis, T. Lazarides and M. J. Manos, Angew. Chem., Int. Ed., 2015, 54, 1651.

25 W. Y. Kim, H. Shi, H. S. Jung, D. Cho, P. Verwilst, J. Y. Lee and J. S. Kim, Chem. Commun., 2016, 52, 8675.

26 Y. Huang, W. Liu, H. Feng, Y. Ye, C. Tang, H. Ao, M. Zhao, G. Chen, J. Chen and Z. Qian, Anal. Chem., 2016, 88, 7429.

27 M. Tanioka, S. Kamino, A. Muranaka, Y. Shirasaki, Y. Ooyama, M. Ueda, M. Uchiyama, S. Enomoto and D. Sawada, Phys. Chem. Chem. Phys., 2017, 19, 1209.

28 P. Kumar, R. Sakla, A. Ghosh and D. A. Jose, ACS Appl. Mater. Interfaces, 2017, 9, 25600.

29 J. Mei, N. L. C. Leung, R. T. K. Kwok, J. W. Y. Lam and B. Z. Tang, Chem. Rev., 2015, 115, 11718.

30 Y.-X. Li, X.-F. Yang, J.-L. Miao and G.-X. Sun, J. Phys. Chem. C, 2016, 120, 21722.

31 S. Ciampi, P. K. Eggers, N. L. Haworth, N. Darwish, P. Wagner, M. L. Coote, G. G. Wallace and C. L. Raston, Chem. Commun., 2015, 51, 4815.

32 G.-F. Zhang, M. P. Aldred, W.-L. Gong, C. Li and M.-Q. Zhu, Chem. Commun., 2012, 48, 7711.

33 N. Zhao, Z. Yang, J. W. Y. Lam, H. H. Y. Sung, N. Xie, S. Chen, H. Su, M. Gao, I. D. Williams, K. S. Wong and B. Z. Tang, Chem. Commun., 2012, 48, 8637.

34 R. Hu, C. F. A. Gómez-Durán, J. W. Y. Lam, J. L. BelmonteVázquez, C. Deng, S. Chen, R. Ye, E. Peña-Cabrera, Y. Zhong, K. S. Wong and B. Z. Tang, Chem. Commun., 2012, 48, 10099.

35 X. Y. Shen, Y. J. Wang, E. Zhao, W. Z. Yuan, Y. Liu, P. Lu, A. Qin, Y. Ma, J. Z. Sun and B. Z. Tang, J. Phys. Chem. C, 2013, 117, 7334 .
36 W. Chen, Z. Zhang, X. Li, H. Ågren and J. Su, RSC Adv., 2015, $5,12191$.

37 T. Chen, Z.-Q. Chen, W.-L. Gong, C. Li and M.-Q. Zhu, Mater. Chem. Front., 2017, 1, 1841.

38 Y. Ooyama, R. Nomura, T. Enoki, R. Sagisaka, N. Tsunoji and J. Ohshita, ChemistrySelect, 2017, 2, 7765.

39 Y. Ooyama, R. Sagisaka, T. Enoki, N. Tsunoji and J. Ohshita, New J. Chem., 2018, 42, 13339.

40 G. Men, C. Chen, C. Liang, W. Han and S. Jiang, Analyst, 2015, 140, 5454.

41 S. Tsumura, T. Enoki and Y. Ooyama, Chem. Commun., 2018, 54, 10144.

42 T. Enoki and Y. Ooyama, Dalton Trans., 2019, 48, 2086.

43 H. Tong, Y. Hong, Y. Dong, Y. Ren, M. Häussler, J. W. Y. Lam, K. S. Wong and B. Z. Tang, J. Phys. Chem. B, 2007, 111, 2000. 44 Y. Ooyama, M. Sumomogi, T. Nagano, K. Kushimoto, K. Komaguchi, I. Imae and Y. Harima, Org. Biomol. Chem., 2011, 9, 1314.

45 Y. Lei, Y. Liu, Y. Guo, J. Chen, X. Huang, W. Gao, L. Qian, H. Wu, M. Liu and Y. Cheng, J. Phys. Chem. C, 2015, 119, 23138.

46 D. Wang, H. Zhao, H. Li, S. Sun and Y. Xu, J. Mater. Chem. C, 2016, 4, 11050.

47 Y. Dong, J. Cai, Q. Fang, X. You and Y. Chi, Anal. Chem., 2016, 88, 1748.

48 S. Guo, X. Xie, L. Huang and W. Huang, ACS Appl. Mater. Interfaces, 2016, 8, 847.

49 A. Wang, R. Fan, Y. Dong, Y. Song, Y. Zhou, J. Zheng, X. Du, K. Xing and Y. Yang, ACS Appl. Mater. Interfaces, 2017, 9, 15744.

50 A. S. Coronilla, C. Carmona, M. A. Muñoz and M. Balón, J. Fluoresc., 2009, 19, 1025.

51 M. Balón, C. Carmona, P. Guardado and M. A. Muñoz, Photochem. Photobiol., 1998, 67, 414.

52 C. Carmona, M. Galán, G. Angulo, M. A. Muñoz, P. Guardado and Q. M. Balón, Phys. Chem. Chem. Phys., 2000, 2, 5076.

53 C. Carmona, M. Balón, M. Galán, G. Angulo, P. Guardado and M. A. Muñoz, J. Phys. Chem. A, 2001, 105, 10334.

54 P.-T. Chou, Y.-I. Liu, G.-R. Wu, M.-Y. Shiao, W.-S. Yu, C.-C. Cheng and C.-P. Chang, J. Phys. Chem. B, 2001, 105, 10674.

55 C. Carmona, M. Balón, M. Galán, P. Guardado and M. A. Muñoz, Photochem. Photobiol., 2002, 76, 239.

56 C. Carmona, M. Balón, A. S. Coronilla and M. A. Muñoz, J. Phys. Chem. A, 2004, 108, 1910.

57 J. Hidalgo, A. Sánchez-Coronilla, M. Balón, M. Asunción Muñoz and C. Carmona, Photochem. Photobiol. Sci., 2009, 8, 414.

58 A. Sánchez-Coronilla, C. Carmona, M. A. Muñoz and M. Balón, J. Fluoresc., 2010, 20, 163.

59 T. Enoki, K. Matsuo, J. Ohshita and Y. Ooyama, Phys. Chem. Chem. Phys., 2017, 19, 3565. 